\title{
Una aproximación antropológica a la justicia transicional y los pueblos indígenas: El caso de Guatemala. Comentario a Lieselotte Viaene, Nimla Rahilal. Pueblos indígenas y justicia transicional: reflexiones antropológicas
}

\author{
(2019) Deusto Digital \\ Bilbao, 166 pp.
}

\author{
Javier Dorado Porras \\ Universidad Carlos III de Madrid \\ ORCID ID 0000-0002-9315-2155 \\ dorado@der-pu.uc3m.es
}

Cita recomendada:

Dorado Porras, J. (2020). Una aproximación antropológica a la justicia transicional y los pueblos indígenas: El caso de Guatemala. Comentario a Lieselotte Viaene, Nimla Rahilal. Pueblos indígenas y justicia transicional: reflexiones antropológicas. Eunomía. Revista en Cultura de la Legalidad, 16, pp. 397-415.

doi: https://doi.org/10.20318/eunomia.2020.5286

Recibido / received: 17/02/2020

La justicia transicional es un campo relativamente novedoso y en el que, no obstante, existe una ingente bibliografía que sigue creciendo a un ritmo vertiginoso y que hace casi imposible estar al día para quienes trabajamos en estos temas. Por supuesto, los trabajos que se publican pueden ser mejores o peores, y tener un mayor o menor interés para quien los lee, dependiendo de numerosos factores más o menos objetivos o subjetivos.

Sin embargo, desde mi punto de vista, el libro de Lieselotte Viaene es una lectura muy interesante para quienes están interesados en la justicia transicional, ya que como la propia autora describe en la introducción, «forma parte de una emergente literatura académica internacional que cuestiona el paradigma de justicia transicional por ser un campo demasiado abstracto, generalista, legalista y con una visión de arriba a abajo». Ciertamente, el trabajo forma parte de esa teoría crítica que desde hace ya algunos años ha empezado a cuestionar muchos de los planteamientos en los que se había situado el mainstream de la justicia transicional. Se trata de un enfoque especialmente necesario en dicho campo, porque a pesar de los consabidos avisos a los que me referiré a continuación y que encontramos en la mayoría de la literatura especializada -tanto académica como práctica-, lo cierto es que el 
mainstream de la justicia transicional sigue adoleciendo de los problemas antes mencionados. Así, se avisa de la necesidad de contextualización, de adaptación de los mecanismos de la justicia transicional a los contextos locales, y de evitar el one size fits all. Sin embargo, vemos a ONG's, gobiernos y Organizaciones Internacionales crear entramados institucionales donde los mecanismos de justicia transicional se replican de un país a otro, en forma de una imitación (mimicry) que choca con dicha necesidad. Se avisa de la necesidad de asumir un enfoque interdisciplinar que incorpore dimensiones de la ética, la política, la sociología, la antropología, etc. Sin embargo, el enfoque sigue siendo eminentemente legalista, a lo que sin duda contribuye -como no deja escapar la autora- el enfoque inicial de la justicia transicional como rendición de cuentas por las violaciones de los derechos humanos y, por tanto, su conexión -en origen- con «la disciplina del derecho internacional de los derechos humanos». Se avisa de la necesaria participación de la ciudadanía -en general- y de las víctimas -en particular- no sólo en los mecanismos transicionales, sino también, y con carácter previo, en su conformación, diseño y creación, afirmando que esto aumentará no solamente su legitimidad sino también su apropiación por parte de la sociedad. Sin embargo, rara vez estos mecanismos son producidos bottom-up en el ámbito nacional-gubernamental. Estos y otros déficits en el campo de la justicia transicional, ha hecho que en los últimos años surja una interesante literatura crítica en este campo, de la que el libro que aquí se reseña forma parte, y que hace alusión a importantes debates sobre el propio concepto, suposiciones, significados y alcances de la justicia transicional. La mayoría de ellos son señalados por la autora en la introducción, haciendo referencia a la relación entre justicia transicional y consolidación de la paz, la relación entre justicia transicional y desarrollo, o la relación entre justicia transicional y género. Ninguno de estos debates, aunque muy interesantes y esenciales para el devenir de la Justicia Transicional, son, no obstante, el objeto de esta obra, que se centra en el debate sobre los «desafíos conceptuales y prácticas que la diversidad cultural de sociedades pluriculturales ha generado en el ámbito de la justicia transicional». Esa imitación (mimicry) a la que me refería anteriormente, y que como dice la autora tiene que ver con el «aumento de modelos globales de justicia transicional, se encuentra, cada vez más, con críticas fundamentadas en particularidades locales y culturales que cuestionan las visiones dominantes sobre los objetivos de este emergente paradigma internacional», alertando sobre la imposición, o al menos la promoción, de «mecanismos occidentales de justicia en sociedades pluriculturales sin tomar en cuenta los recursos culturales ya existentes». Así, el trabajo que se reseña, dedicado a la justicia transicional y pueblos indígenas en Guatemala, tiene como objetivo principal «contribuir a reducir la brecha de conocimiento en torno a entendimientos y prácticas indígenas de justicia, reparación, búsqueda de la verdad y reconciliación para enfrentar las graves violaciones de derechos humanos sufridas durante el conflicto armado» y, de esta forma "fomentar un proceso de reflexión crítica para desafiar y repensar tanto el paradigma dominante de la justicia transicional como los derechos humanos en general cuestionando su dogma antropocéntrico». Lo hace desde un enfoque eminentemente interdisciplinar que conjuga los campos de los derechos humanos, la justicia transicional y la antropología jurídica para responder a una pregunta principal de investigación que incluye una dimensión doble, analizando los factores culturales que pueden suponer obstáculos difíciles de superar para la justicia transicional así como aquellos que pueden permitir que determinados entramados transicionales se contextualicen de forma exitosa a nivel local. Para ello, la autora realizó un estudio de caso de Guatemala, con una investigación etnográrfica multisitio entre víctimas y ex patrulleros de Autodefensa Civil Indígenas maya q'eqchi' durante dos años, con el fín de comprender cómo los sobrevivientes q'eqchi' «entienden y perciben los objetivos de la justicia transicional y las intervenciones estatales en esta materia en sus comunidades». Sin embargo, el estudio intenta trascender el contexto descriptivo del estudio de caso para ofrecer reflexiones útiles 
a la doctrina y la práctica de la justicia transicional cuando se enfrentan a su implementación en sociedades pluriculturales en conflicto o post-conflicto, y que se recogen en el capítulo final de conclusiones y recomendaciones.

Por mi parte, haré un repaso más bien descriptivo de cada uno de los capítulos del libro, aunque iré introduciendo algunas reflexiones sobre aquellos aspectos del trabajo sobre los que, debido a mi trayectoria investigadora en el ámbito de la justicia transicional, me siento más capacitado para incursionar, pensando principalmente en mi nula formación antropológica.

Así, el capítulo 1, titulado «justicia transicional y desafíos culturales» opera como una introducción previa al grueso de dicho estudio de caso sobre Guatemala, analizando, por un lado, algunos de los contextos iniciales en los que dentro del marco de la justicia transicional surgió el cuestionamiento cultural al paradigma dominante y que se plantean dentro de la dicotomía que en el campo de los derechos humanos puede definirse como la tensión universilidad vs. relativismo cultural; y por otro, el nexo entre justicia transicional y pueblos indígenas. Respecto al primero de los temas, este capítulo empieza incursionando, aunque de forma muy breve, en cinco contextos -4 de ellos en Africa y uno en Asia- en los que los entramados transicionales de diferentes sociedades recurrieron a su propia tradición-cultura para incorporarla a los mecanismos transicionales: los Tribunales Gacaca, en Ruanda; la idea de Ubuntu, en Sudáfrica; el rol de los líderes tradicionales en las comisiones de la verdad de Sierra Leona y Timor Oriental; y la justicia tradicional local, en el caso de Uganda. Coincidiendo con la autora en la selección de los casos, me parecen especialmente relevantes tres de ellos, aunque por distintas razones.

Por un lado, tenemos el caso sudafricano, con la superación del régimen del apartheid y la andadura hacia una democracia racialmente inclusiva a través del concepto de Ubuntu -que podría traducirse como humanidad o grandeza de espírituy que concretó en sí mismo la mentalidad del entramado transicional sudafricano, y especialmente de la Comisión de la Verdad y la Reconciliación (CVR), tendendente al respeto a los derechos humanos, la satisfacción de la justicia restaurativa y la producción de reconciliación y construcción nacional. Es un caso diferente a los otros dos a los que me referiré posteriormente porque se trata de un contexto que no planteó prácticamente ningún dilema en la comunidad internacional, y de hecho, se trata de una transición que contó con un gran apoyo externo. Las sesiones de la CVR fueron seguidas y retransmitidas incluso internacionalmente, y el sistema de intercambio de verdad por amnistía -amnistías individuales otorgadas por el comité de amnistías de la CVR-mayoritariamente defendido como la única forma de acceder a un conocimiento más pleno e integral de las violaciones de derechos humanos ocurridas durante el régimen anterior y que permitiría a las víctimas y a los perpetradores pasar página, manifestado en el lema de la CVR, «revealing is healing». Soy consciente, y no es por tanto una crítica, que la autora solamente utiliza estos casos como precedentes iniciales de esa pluriculturalidad requerida también en el contexto de la justicia transicional, precisamente para adaptarla al contexto local ese aviso tantas veces hecho en este campo y tan poco utilizado-. De ahí que solo se le dediquen a estos casos cinco páginas, más a efectos divulgativos que de análisis más profundo, entiendo. Sin embargo, esta excusa me brinda la oportunidad de detenerme más detalladamente en algunos aspectos del caso sudafricano que me parecen muy interesantes. Por un lado, hay que tener en cuenta que normalmente se habla del caso sudraficano en clave de gran éxito, hasta el punto de que este contexto transicional supuso, en el caso concreto de las comisiones de la verdad, el despegue definitivo de este instrumento. Tanto es así que desde el ejemplo sudafricano prácticamente no hay ningún contexto transicional que no incorpore una comisión de la verdad y que no incluya en el nombre de esta alguna apelación a la reconciliación. 
Por otro lado, no debe olvidarse que numerosos trabajos académicos han puesto de relieve que esa supuesta reconciliación no ha sido tan exitosa como se quería hacer creer. Así, en primer lugar, debe tenerse en cuenta que al menos algunas víctimas de las que desfilaron por las sesiones de la CVR no encontraron el consuelo esperado, al tener que confrontar a los perpetradores que participaron en la misma, aunque esto es algo inevitable si pensamos en la amplitud del universo de víctimas en contextos transicionales y en las diferentes necesidades, intereses y reclamos que las víctimas pueden tener. Más preocupante me parece, sin embargo, el hecho de que gran parte de los problemas planteados con el proceso de reconciliación pretendido tuvieron que ver no tanto con la utlización de conceptos culturales-tradicionales -como el Ubuntucomo con el propio diseño del mandato de la CVR, centrada en la tensión entre víctimas de violaciones de los derechos civiles y políticos -comúnmente activistas políticos-vs. perpetradores -normalmente fuerzas de seguridad del estado-. Muchos académicos y víctimas proponían un enfoque alternativo y más amplio, centrado en la tensión entre los beneficiarios del régimen de apartheid -la minoría blanca- vs. víctimas de violaciones de derechos en general -la mayoría negra que había sufrido los desplazamientos forzados y la privación de sus modos de vida-. Según ellos, el enfoque estrecho de la CVR y la no preocupación por los derechos económicos, sociales y culturales ha supuesto el paso de un apartheid político en el pasado a un apartheid económico en la actualidad. Por tanto, es importante no perder de vista el enfoque multicultural, pero también otras aspectos más de diseño institucional que pueden afectar también de forma muy importante a los resultados de la transición. Finalmente, y para dejar ya el caso sudafricano, no debe olvidarse tampoco que la configuración de la transición sudafricana, muy basada en el Ubuntu, la reconciliación e incluso el perdón, no era aceptado por todas las víctimas y sectores sociales. En este sentido, no deja de resultar curioso, que el grupo político que más fuertemente se opuso al entramado transicional sudafricano -AZAPO- sea el partido político que más fuertemente ha criticado las continuidades del régimen colonial y las resistencias de la decolonización en la actual sudáfrica. AZAPO, junto con Nontsikelelo Margaret Biko - viuda del conocido activista Steve Biko asesinado en prisión durante el régimen del apartheid- y otras personas, llegaron hasta el Tribunal Constitucional de Sudáfrica (Case CTT 17/96, de 1996) para solicitar la inconstitucionalidad del sistema de amnistías establecido durante la transición por vulneración del derecho a la tutela judicial efectiva, aunque finalmente el tribunal mantuvo su constitucionalidad.

Más problemas han planteado a la comunidad internacional los casos de los tribunales Gacaca en Ruanda y el uso de la justicia tradicional en Uganda.

El primero de los casos ha planteado el debate entre los defensores de derechos humanos especialmente con respecto al respecto a los derechos de debido proceso, como hace evidente, entre otros, el informe de Human Rights Watch de 2011 titulado "Justice Compromised. The legacy of Rwanda's Community-Based Gacaca Courts». En todo caso, son varios los trabajos, algunos de ellos citados en el libro que se reseña, que han manifestado su posición, a pesar de ciertas sombras, favorable con los Tribunales Gacaca como un esfuerzo útil y adecuado por integrar la justicia tradicional en la justicia transicional y sus fines.

El segundo, el caso de Uganda, es desde mi punto de vista el más problemático y como afirma Lieselotte Viaene, se ha convertido «en el centro de los debates clave y complejos sobre la paz versus justicia, y la justicia retributiva internacional occidental versus la justicia trandicional local». Me permito remontarme a un momento anterior al recogido en el libro que se reseña para explicar de forma más completa el caso. En el año 2000, el gobierno ugandés aprueba una Ley de Amnistía que tiene un amplio apoyo por parte de la población, especialmente en el norte del país, y para la que habían hecho lobby las autoridades de la comunidad 
Acholi y los líderes religiosos. Se trata de una amnistía que se configura como una amnistía individualizada condicionada a que los solicitantes se rindan, se desarmen y renuncien al uso de la violencia y que cubre todos los crímenes del conflicto realizados por actores no estatales, incluyendo los líderes de los grupos insurgentes. Sin embargo, inmediatamente después de su aprobación, el gobierno ugandés expresó su intención de excluir de la misma -y buscar la persecución penal- a los «más responsables» de las violaciones cometidas por el Lord's Resistance Army (LRA), a través de la remisión del caso a la Corte Penal Internacional. Por su parte, la Corte Penal Internacional emite, en julio de 2005, ordenes de arrestro contra el jefe del LRA, Joseph Kony, y sus principales comandantes -Vincent Otti, Okot Odhiambo, Dominic Ongwen y Raska Lukwiya- que tiene como resultado una modificación de la ley de amnistía en el 2006 que atribuye al ministro de asuntos exteriores la posibilidad de convertir en inelegibles para la amnistía a individuos concretos, pensada precisamente para excluir de la misma -y evitar conflictos- a los jefes del Lord's Resistance Army anteriormente citados. A pesar de las peticiones de la comunidad y los líderes religiosos Acholi a la Corte Penal Internacional para que retire las ordenes de arresto, por el peligro de perpetuación del conflicto que suponen, la oficina del fiscal de la Corte -Luis Moreno Ocampo- emite un comunicado de prensa ese mismo año en el que manifiesta su intención de continuar con la investigación del caso, lo que pone en peligro las negociaciones de paz y obliga al presidente del país a manifestar públicamente que si Kony se acogía a la amnistía disfrutaría de la misma. Así, las conversaciones de Paz de Juba (2006-2008) incorporan esta idea y la posibilidad de aplicación del sistema tradicional de reconciliación Mato Oput de la comunidad Acholi, de la que forma parte el líder del LRA, Joseph Kony. Sin embargo, estas conversaciones tampoco tendrían un fin exitoso debido, principalmente, al mantenimiento de las ordenes de arresto por la Corte Penal Internacional, que se convirtieron en el mayor obstáculo para alcanzar la paz negociada en la zona.

Desde mi punto de vista, el caso ugandés demuestra mejor que ningún otro como los posicionamientos de la comunidad internacional -especialmente en el ámbito de Naciones Unidas- en defensa de la más amplia persecución penal posible como lucha contra la impuniad y de una política de tolerancia cero contra las amnistías pueden suponer un grave peligro para los derechos humanos en muchas zonas del mundo, a través de la perpetuación de conflictos que, sin salida negociada y sin transacción por ambas partes, será difícil revertir. Además, esta posición de la comunidad internacional, y el rol de la Corte Penal Internacional en su desarrollo, ha tenido un impacto muy negativo especialmente en Africa, donde muchos países han criticado no solamente que los primeros casos de la Corte fueran exclusivamente en Africa, sino también la política de tolerancia cero respecto a las amnistías e incluso han amenazado con bajarse del tren de la Corte Penal Internacional, vista como el mayor exponente del neo-imperialismo judicial occidental. En este sentido, el paradigma global de la justicia transicional debería dejar de lado sus postulados maximalistas y uniformantes y, como afirma Lieselotte Viaene, «sacar lecciones aprendidas de los avances en el debate de universalidad-diversidad y de la supuesta oposición de cultura y derechos en el derecho internacional de los derechos humanos (...) la universalidad no requiere uniformidad. El aprendizaje clave es que los derechos humanos universales pueden acomodar diferencias culturales; podemos promover los derechos humanos universales y respetar la diversidad al mismo tiempo (...) la acomodación de la diversidad cultural no debe ser percibida como una amenza, sino como la clave para el fortalecimiento de la universidad de los derechos humanos».

En cuanto a la segunda parte del capítulo primero, dedicado al nexo entre justicia transicional y pueblos indígenas -después de reconocer la labor fundamental del cabildeo durante años de los pueblos indígenas en la comunidad internacional para el reconocimiento y adaptación de los derechos humanos a su situación y su 
aspecto colecitivo y el reconocimiento por ésta de dichos derechos principalmente a través del Convenio 169 de la OIT y la Declaración sobre Derechos de los Pueblos Indígenas- se centra en el análisis de los derechos colectivos de consulta, participación y consentimiento sobre medidas legales y administrativas que les puedan afectar directamente así como el derecho a administrar su derecho propio. Respecto de los primeros, resalta no solamente la gran brecha entre el reconocimiento de los mismos y su implementación práctica, sino también la casi nula inexistencia de los mismos en contextos transicionales, incluso en aquellos en los que la gran mayoría de sus beneficiarios son víctimas indígenas. Respecto del segundo el derecho a administrar su propio derecho- la autora pone el énfasis, como no podría ser de otra forma, en América Latina, donde ha habido importantes avances en el reconocimiento constitucional de los sistemas de justicia indígena, así como en la cooperación y coordinación de ésta con la jurisdicción ordinaria estatal, aunque -de nuevo- resaltando como el papel de estos sistemas tradicionales de justicia en los contextos transicionales sigue siendo también casi nulo, operando además la competencia para crímenes internacionales como un límite al pluralismo jurídico.

Por lo que respecta al capítulo 2, titulado «localizar la justicia transicional entre víctimas y victimarios indígenas en Guatemala», tiene una doble finalidad. Explorar por qué el caso de Guatemala es especialmente valioso para investigar el rol del contexto cultural en los procesos de justicia transicional a través de las características generales y algunos datos sobre el conflicto armado que afectó a este país durante treinta y seis años, y analizar las características y componentes del diseño de investigación sobre el que se sustenta el trabajo.

En el primero de estos aspectos, el trabajo, después de recordar que los grupos indígenas maya no son la cultura dominante, a pesar de representar el 60$70 \%$ de la población, se hace un breve repaso de las violaciones de derechos humanos cometidas, utilizando datos de la Comisión para el Esclarecimiento Histórico (CEH) y centrándose en las dimensiones más interesantes de las mismas que permiten extraer ciertas consideraciones sobre las mismas. En primer lugar, pueden considerarse como actos de genocidio contra el pueblo maya, a pesar de que, como la misma autora reconoce, «hasta el día de hoy, la cuestión de si hubo o no genocidio en Guatemala sigue generando un fuerte debate jurídico y político»; En segundo lugar, se trata de un ejemplo de crímen «íntimo» (dimensión muy localizada en las propias comunidades y participación masiva de civiles en las atrocidades, lo que supone una mayor afectación a la cohesión social) mediante la imposición de las Patrullas de Autodefensa Civil (PAC) en las comunidades rurales indígenas, en las que llegaron a participar en su momento más álgido más de un millón de hombres indígenas. Las PAC eran obligadas a hacerse cargo de tareas militares, siendo responsables de alrededor del $18 \%$ de las violaciones de los derechos humanos cometidas durante el conflicto, principalmetne captura o ejecución de guerrilleros, torturas y violaciones sexuales, lo que no solamente hace muy difícil de utlizar la dicotomía victima-victimario -algo, por otro lado, bastante común en el marco de la justicia transicional- sino que, como manifestó la $\mathrm{CEH}$, tuvo un impacto perverso en la cohesión social y la acción colectiva de dichas comunidades.

Posteriormente, se hace un anális de los Acuerdos de Paz, para insistir en la idea de que el alto nivel de violencia e inseguridad post-conflicto en el país no responde tanto a su incumplimiento como al hecho de que los mismos «nunca respondieron directamente y de forma adecuada a las causas estructurales subyacentes del conflicto armado» ni «incorporaron de forma suficientes las demandas culturales históricas de la población indígena, como la redistribución y el control de la tierra o la autonomía política y territorial». Según la autora, los mismos deberían haber incluido «provisiones y metas importantes, como el fortalecimiento de 
la administración tributaria, la adaptación de políticas económicas tendentes a alcanzar un crecimiento sostenido del producto interno bruto, la creación de un fondo fideicomiso de tierras y un registro del catastro, el reconocimiento de las formas organizativas indígenas, el derecho consuetudinario, las lenguas y espiritualidades indígenas, los sitios sagrados y la vestimenta tradicional». Sin embargo, los Acuerdos de Paz presentaron serias lagunas de las que se pueden extraer varias consecuencias. En primer lugar, Guatemala sigue siendo un estado multicultural débil, ya que los acuerdos no reconocieron el derecho colectivo de los pueblos indígenas a la tierra, al territorio y a los recursos naturales a pesar de haber ratificado en 1996 el Convenio de 169 de la OIT y ser estos derechos básicos para la supervivencia de dichas comunidades, que se están viendo amenzadas en los últimos años por megaproyectos extractivos como ha indicado la Oficina del Alto Comisionado de las Naciones Unidas para los Derechos Humanos. En segundo lugar, sigue habiendo una ausencia de una política pública clara de justicia transicional en coordinación con los diversos actores de la sociedad civil, lo que convierte a este entramado institucional en un «masaico de esfuerzos oficiales y no oficiales que carecen de conexión y visión integral e intercultural», debido a la falta de voluntad política, la discriminación y el racismo institucional promovidos por las élites del país, beneficiarias de las desigualdades extremas. De ahí que los avances logrados en Guatemala se deban más a los esfuerzos de las organizaciones de víctimas y el apoyo de la comunidad internacional, entre los que cabe destacar la propia creación de la CEH y ciertas iniciativas de persecución penal, especialmente el juicio por genocidio contra Ríos Montt, anulado posteriormente por la Corte Constitucional.

La segunda parte de este capítulo se encarga, como se explicó anteriormente, de explicitar el diseño de la investigación sobre el que se sustenta el trabajo, y que pretende, como afirma la autora, «contribuir a llenar el vacío existente en la literatura antropológica que investiga desde las ontologías y sistemas normativos indígenas cómo los sobrevivientes q'eqchi' perciben los mecanismos de justicia transicional y cuál ha sido el impacto de los diversos esfuerzos de búsqueda de justicia, reparación, compensación y reconciliación a nivel individual, interpersonal y colectvo en las comunidades». El objetivo central de la investigación es, por tanto, analizar de qué manera las particularidades de la cultura y cosmovisión maya q'eqchi' desempeñan un papel en los procesos de justicia transicional que se desarrollan en las comunidades afectadas pro el conflicto armado interno. Así, la investigación de campo debía responder a 8 cuestiones iniciales: 1) ¿Cómo han entendido culturalmente las víctimas y ex-patrulleros q'eqchi' las violaciones de derechos humanos sufridas durante el conflicto armado?; 2) ¿Cómo perciben los objetivos principales de justicia transicional?; 3) ¿Cuál es el significado que atribuyen a conceptos como justicia, reparación, búsqueda de la verdad y reconciliación?; 4) ¿Cómo se vinculan estos significados con su cosmovisión y su sistema normativo?; 5) ¿De qué manera están restaurando las relaciones sociales fragmentadas en sus comunidades?; 6) ¿Qué factores fomentan y/o dificultan dicha restauración?; 7) ¿Cuáles son las percepciones que tienen sobre las intervenciones (inter)nacionales de justicia transicional?; y ¿de qué manera estas intervenciones toman en cuenta las realidades locales y culturales de sus comunidades?

Para abordar estas preguntas la autora realiza una investigación de campo etnográfica multisituada, desde un enfoque antropológico jurídico y con aplicación de una triangulación metodológica y dedica el resto del capítulo segundo a exponer qué significan cada una de estas dimensiones. Así, se habla de investigación multisituada porque se intenta «rastrear ideas y prácticas que están circulando y procesos translocales, así como examinar conexiones y contrastes, cruzando diferentes lugares». Para ello, la autora realiza trabajo de campo durante casi dos años -entre 2006 y 2012- en tres microrregiones del municipio de Cobán, en el departamento de 
Alta Verapaz: Nimlasachal, Nimlaha'kok y Salacuim. Se trata, además, de un enfoque antropológico-jurídico, y en este sentido, como afirma la autora, no debe olvidarse que la antropología jurídica ha hecho importantes contribuciones en el campo de los derechos humanos, ayudando a una mejor comprensión de «cómo los derechos humanos funcionan en el terreno qué impacto real tienen y cómo el derecho internacional se traduce en la justicia local»-como demuestra la realización de peritajes antropológicos para apoyar las interpretaciones legales de los casos concernientes a pueblos indígenas solicitados por múltiples tribunales nacionales en América Latina o por la propia Corte Interamericana de Derechos Humanos-. Igualmente, puede ayudar en el campo de la justicia transicional ilustrando «cómo sobrevivientes y comunidades movilizan elementos rituales y simbólicos de justicia transicional para enfrentar los abismos profundos creados -o acentuados- por conflictos civiles». Finalmente, se aplica una triangulación metodológica, o múltiples técnicas de colección de datos, combinando diferentes métodos y enfoques metodológicos con el fin, en palabras de la autora, «de producir conocimientos a difetentes niveles (locales, regionales y nacionales) y de comparar y vincular los datos etnográficos producidos». Entre los diferetnes técnicas, métodos y enfoques se encuentran: 1) estudio etnolingüístico y talleres etnolingüísticos; 2) observación participante; 3) grupos focales semiestructurados con enfoque intercultural; y 4) entrevistas individuales formales e informales.

El capítulo 3, titulado «El conflicto armado interno en el territorio q'eqchi': una visión desde abajo", inicia lo que es el núcleo del trabajo, con una triple dimensión. En primer lugar, se hace un revisión del despojo y del espolio sistemático de sus tierras al que ha sido sometido el pueblo indígena q'eqchi' desde la época de la conquista. En segundo lugar, se presentan algunos rasgos centrales de la cosmovisión u ontología e identidad q'eqchi'. Finalmente, se examina el impacto sobre este pueblo que ha tenido el conflicto armado, tanto en cifras como desde un perspectiva de entendimiento indígena.

Resulta, en este sentido, interesante resaltar, respecto a la primera cuestión, la identificación que se traza en las primeras páginas del capítulo de la distribución desigual de la tierra como una de las causas principales del conflicto armado, algo que no es propio exclusivamente del contexto guatemalteco sino de muchos contextos transicionales, especialmente a partir de la ampliación de estas prácticas originadas en contextos de transición democrática- al campo de los conflictos armados. Ciertamente, gran parte de los conflictos armados se producen en sociedades mayoritariamente agrarias, y la cuestión de la tierra es un factor determinante no solamente en el origen de los mismos sino también en su finalización, por lo que no es raro que los instrumentos o mecanismos de justicia transicional especialmente las comisiones de la verdad, los programas de reparación y las reformas legales e institucionales- hagan referencia constante a este tema, incluso incluyendo una perspectiva de género. En el caso concreto de Guatemala, esa injusta distribución de la tierra, por lo que hace especialmente al pueblo q'eqchi', es la causa principal de su pobreza y exclusión social y tiene como origen las expropiaciones sistemáticas iniciadas desde la conquista hata hoy. Son, en este sentido, muy ilustradoras estas páginas del trabajo, en las que Lieselotte Viaene, hace un repaso muy sintético y, a la vez, preciso del devenir de dicho espolio, conectándolo además con datos estadísticos que permiten de alguna forma justificar también la elección del lugar donde se realiza el estudio de campo, ya que el departamento de Alta Verapaz, en el que se encuentra el municipio de Cobán -y más en concreto las 3 microrregiones en las que tiene lugar el estudio multisituado- es el que presenta el índice más alto de conflictividad agraria. La conclusión no puede ser discutida: los «flujos de migración rural de una población pobre y sin tierra, como este grupo indígena, no son una elección sino su única opción para la supervivencia cultural al despojo forzoso y 
explotación laboral continua desde la conquista. Por lo cual podría nombrar a los q'eqchi' como un pueblo víctima de despojo forzoso histórico y sistemático. Es decir, en términos de derechos humanos, el Estado Guatemalteco ha omitido proteger y promover hasta hoy día el derecho colectivo de los q'eqchi' a la tiera y al territorio».

No menos interesante resulta la siguiente parte de este capítulo, dedicada a realizar una aproximación a la cosmovisión y ontología q'eqchi', en un esfuerzo por intentar acercar a las mentes occidentales una forma de ser y estar en el mundo absolutamente diferente para nosotros y que entiendo que es compartida con la mayoría -si no por la totalidad- de los pueblos indígenas. Partiendo de la advertencia de que las comunidades q'eqchi' son entidades heterogéneas y complejas, y están cracterizadas por la diversidad política, religiosa y económica, se sitúa como rasgo clave común en sus cosmovisiones la idea de que los seres humanos deben ser entendidos como "seres relacionales», rechazando la división entre cultura y naturaleza occidental y reflejando una visión mucho más unitaria, interrelacionada e interdependiente de todos los elementos que componen el mundo. Así, los q'eqchi' no son solamente individuos, sino que están estructurados por sus relaciones con la familia, la comunidad, la tierra y el territorio, el mundo espiritual, las energías, etc. La primera conclusión absolutamente relevante, desde mi punto de vista, tiene una enorme relevancia en tiempos de preocupación por el destino de nuestro planeta: los seres humanos no son dueños de la naturaleza, sino que forman parte de ella y esto supone una relación de respeto hacia la misma -una conexión física y espiritual- que en la cultura occidental -si alguna vez existió- hace mucho que se perdió y que nos acerca cada vez más al precipicio. Para ellos, todo tiene vida, incluidos los recursos naturales, y debe ser protegido igual que la vida humana. Toda esta cosmovisión u ontología, ha sido, como resalta la autora, el fundamento de estos pueblos para cuestionar el enfoque liberal-individualista de los derechos humanos y reinvindicar en el orden internacional sus derechos colectivos, y determinará también, como se verá más adelante, su comprensión tanto del conflicto armado como de los instrumentos de justicia transicional. Su relación especial -no solamente física sino espiritual- con la tierra y el territorio y la unidad entre lo social, lo natural y lo espiritual -concretada principalmente en la nociones de lo sagrado (Loqlaj), la cohesión social (Junajil) y tranquilidad/armonía/equilibrio (Tuqtuukilal) - juegan un papel vital en los procesos locales de justicia transicional y en cómo los q'eqchi' «interpretan y entienden la justicia, la reparación, la compensación, la verdad y la reconciliación, objetivos centrales de la justicia transicional (...)».

Finalmente, este capítulo analiza el conflicto armado desde dos puntos de vista, el de las cifras y datos, y el del propio entendimiento q'eqchi' del mismo. No voy a detenerme mucho en el primero, salvo para ofrecer algunas informaciones que puedan ayudar a comprender mejor las elecciones hechas por la autora de este trabajo. Así, merece la pena destacarse que el informe de la CEH demuestra que el grupo étnico q'eqchi', en términos generales, fue el segundo grupo maya afectado en cantidad de violaciones a los derechos humanos, y que el informe del REMHI (segunda iniciativa de búsqueda de la verdad patrocinada por la iglesia católica a través de la Oficina de Derechos Humanos del Arzobispado de Guatemala como un proyecto interdiocesano de Recuperación de la Memoria Histórica) afirma que fueron la etnia con mayor número de víctimas a nivel nacional. Por otro lado, Alta Verapaz departamento en el que como ya se ha dicho, se realiza el estudio multisitio- fue el tercer departamento más golpeado por el conflicto. En el área de Cobán, concretamente, más de 40 comunidades fueron destruidas por lapolítica de tierra arrasada del ejército y se registraron un total de 1.708 víctimas, de las que el $52 \%$ fueron asesinadas en sus comunidades mientras que el $48 \%$ murió por enfermedad, inanición, etc. Se estima que en Alta Verapaz, al menos un $40 \%$ de los q'eqchi' fueron desplazados de sus comunidades y unos 20.000 de ellos se escondieron por años en 
las montañas, haciendo frente a condiciones extremas y cambiando constantemente de ubicación al ser perseguidos, y muchos de ellos murieron también de hambre, enfermedades o "susto». Con la amnistía ofrecida por el gobierno de Rios Montt en 1982 y su política de promover el retorno masivo de los desplazados, muchos de ellos decidieron volver de las montañas y fueron trasladados a campamentos militares 0 «polos de desarrollo» donde fueron sometidos a reeducación ideológica y dependieron, durante años, de la ayuda de emergencia y del régimen de «alimentos por trabajo», además de ser obligados -en el caso de los varones- a integrarse en las PAC. Posteriormente, hacia finales de los 80 , se clausuraron los campamentos militares y los desplazados tuvieron que reubicarse e integrarse en el departamento de Alta Verapaz, sufriendo humillaciones, acusaciones y amenazas de las PAC y de los que se habían quedado en las aldeas. Como dice la autora, el ejército «había creado un clima de temor y hostilidad, como parte de su guerra psicológica, causando una profunda desconfianza contra los de la montaña (aj rub'el pim), que eran vistos como guerrilleros. La búsqueda de tierra en la región causó fricciones entre los sobrevivientes y dividió a los grupos y a las familias. Los retornados de México pudieron contar con apoyo de la comunidad internacional y del Estado para comprar tierras, mientras los desplazados internos quedaron en el olvido».

Todavía más interesante resulta, a mi modo de ver, la parte dedicada al entendimiento q'eqchi' del conflicto armado desde su ontología y cómo el mismo difiere de forma importante de las visiones sobre violaciones de derechos humanos provinientes del paradigma dominante en el derecho internacional. La razón, como sintetiza la autora, es que esta diferencia es «clave para la elaboración de políticas e intervenciones de justicia transicional intercultural que responda[n] a las aspiraciones y necesidades de los sobrevivientes indígenas». Los q'eqchi' se refieren a la etapa del conflicto armado como nimla rahilal. Nimla significa grande, y rahilal, sufrimiento y dolor (tanto físico como emocional y espiritual) por una pérdida definitiva (de familiares o bienes) que implica un daño irreparable. El conflicto armado provocó, para ellos, no solamente violaciones (muxuk) de sus derechos humanos individuales, sino también de sus normas sociales y espirituales, que suponen la destrucción de su tuqtuukilal (tranquilidad/armonía/equilibrio) y su junajil (cohesión social). Según su visión, en el conflicto armado $x O^{\prime}$ e'xmux, que significa unos profanaron a los humanos y al cosmos», lo que refleja que esa profanación va mucho más allá de lo humano, incluyendo también lo natural y espiritual y supuso un q'tok (doblar) de su mundo que implica un trauma colectivo a nivel comunitario imposible de borrar: «el dolor nunca saldrá de nuestro corazón (li rahilal ma jo' tahelq s qach'ool')». Se habla, en definitiva, desde una comprensión de las violaciones muy diferente al paradigma dominante de los derechos humanos y su concepción antropocéntrica e individualista de los mismos, así como de su concepción dualista sujeto/objeto, naturaleza/cultura y humano/no humano.

Por su parte, el capítulo 4, titulado «La relevancia de conceptos indígeneas de justicia y reconciliación», analiza las comprensiones de los sobrevivientes q'eqchi' sobre estos conceptos clave de la justicia transicional, con un propósito doble. Por un lado, contribuir al debate internacional sobre la formalización del rol de la justiticia tradicional en procesos de justicia transicional. Aunque, como recoge la autora en su trabajo, ya se han iniciado movimientos -incluso de actores internacionales- para incorporar la justicia tradicional al toolkit de la justicia transicional-como los casos explicados en el capítulo primero-lo cierto es que la mayor parte se han concentrado en el continente africano, mientras que en los contextos de post-conflicto en los países latinoamericanos pluriculturales -continente con mayor presencia de pueblos indígenas- estas cuestiones culturales prácticamente no han aparecido. Por otro lado, mediante un análisis empírico sobre cómo son vividas y construidas la justicia y la reconciliación en el contexto de las comunidades q'eqchi' en Guatemala, el capítulo 
intenta aportar reflexiones que sirvan para llenar ese vacío en este espacio geográfico.

El punto de partida, que será cuestionado en este capítulo, es el dogma clave en el derecho internacional de los derechos humanos de que todas las víctimas desean el uso de la justicia penal contra los perpetradores de las violaciones y que, por tanto, la lucha contra la impunidad -y el castigo penal- son el fín de la rendición de cuentas. En este sentido, la autora afirma -aunque erróneamente- que «desde el punto de vista maya q'eqchi', la impunidad -tal como se define en el derecho internacional- no es el fin de la rendición de cuentas de los victimarios» (sustitúyase el término «impunidad»-que la autora utiliza así en las páginas 26, 95 y 107-por el término opuesto de «castigo penal», y la frase cobrará todo el sentido).

¿Cómo es entonces la justicia en las comunidades q'eqchi'? Lo primero que deja clara la metodología utilizada por la autora, a través del uso de grupos focales, es que los q'eqchi' casi nunca exigían persecución judicial contra los responsables y autores de las violaciones. Solamente algunas personas líderes, que habían recibido capacitación en derechos humanos, mencionaban «hacer justicia» como algo necesario, aunque tampoco como primera preocupación. Las razones para entender esta ausencia del castigo penal, sobre la base del análisis de los datos etnográficos son las siguientes: 1) existen muchas víctimas que no conocen las raíces y razones del conflicto y quiénes eran las personas en el poder en ese momento; 2) sobre las violaciones de las PAC, hay muchas personas que entienden que fueron obligados a cometer dichas atrocidades por el ejército; 3 ) los sobrevivientes no entienden los beneficios del castigo penal -la justicia corresponde a una lógica interna del cosmosy consideran, además, que quienes estén en la cárcel no les pueden ayudar. Para entender esa lógica interna del cosmos, hay que comprender el concepto de q'oqonk ( $q^{\prime} \circ q$ es su raíz) que se relacionó con la idea de justicia en las entrevistas realizadas como objeto del trabajo. La violación (muxuk) produce un q'oq, «un dolor o tristeza que siente alguien o algo por ser tratado mal, y que se convertirá en un castigo retribuyente al causante del dolor o tristeza». La transgresión -y la desarmonía que produce- no se puede reparar, porque es imposible regresar a la situación original, pero puede ser transformada en un nuevo estado de armonía y equilibrio (Tuqtuukilal) mediante la introducción de la vergüenza, el consejo y la orientación al infractor, para que reconozca su falta y pida perdón. En este proceso de corrección y educación, la familia, los ancianos y las autoridades tienen un papel clave. Pero además, las transgresiones también son resueltas mediante la intervención espiritual, de forma que la lógica interna del cosmos asegura que la desarmonía causada en las relaciones sociales y espirituales sea superada a través de una nueva situación de armonía. El resultado es el q'oqonk', por el que el transgresor sufre un accidente fatal, padece una enfermedad que no se puede curar, etc., como una consecuencia retribuyente que no será sufrida en el más allá, sino en este mundo, sea por el causante o por sus hijos o nietos, y que restaura el equilibrio.

¿Y la reconciliación, cómo es en las comunidades q'eqchi'? En el idioma q'eqchi' no existe un equivalente claro de la palabra «reconciliación». Partiendo de los datos lingüísticos, se argumenta que la unidad de las expresiones kuyuk maak (aguantar la falta, el error) y k'amok ib sa usilal (llevarse en la bondad) refleja esta idea de reconciliación. El causante de la falta (maak), del dolor y el sufrimiento, es la persona que en primera instancia tiene que aguartarla (kuyuk), reconocerla, ya que no se puede reparar. La persona dañada se llevará bien con el causante de su sufrimiento, después de haber aceptado la falta, de aguantarla, y conducirse a ese espacio común donde llevarse con bondad y que produce un nuevo estado de armonía a través de ofrendar a Dios/Tzuul taq'a/ser supremo. De esta forma, los q'eqchi' «guardan una actitud consciente de no actuar en contra de los responsables 
de violaciones de derechos humanos. Esta no actuación está basada en su código ético y moral, en las bases filosóficas de su sistema normativo».

En relación con el conflicto armado, la autora señala como el q'oqonk' es una forma holística e integral de justicia transicional frente a las atrocidades cometidas por victimarios indígenas. Primero, dicha lógica interna del cosmos se encarga de ellos, poniéndoles en una situación opuesta -sin poder o autoridad-a la que tenían durante el conflicto y de vergüenza, no sólo frente a sí mismos, sino también frente a sus familias, comunidades y víctimas. Pero además, el hecho de que los responsables locales estén pagando por su conducta tiene, a la vez, un efecto reparativorestaurativo en las víctimas, porque ellas reciben, mediante el $q^{\prime} \circ q^{\prime}$, reconocimiento de su sufrimiento y tristeza. Además, el q'oqonk no solo atiende al problema individual entre víctima y victimario, sino que lleva el problema y su solución al ámbito comunitario o colectivo, estableciendo una prohibición que se debería respetar, y que cumple, por tanto, un rol también educativo.

La conclusión parece evidente: «existen múltiples maneras de entender y actuar en procesos de justicia transicional que están enclavadas en otras ontologías. Estos otros saberes son manifestaciones del sistema normativo y la cosmovisión indígenas, [que] difieren profundamente de los conceptos hegemónicos del paradigma dominante de justicia transicional. De hecho, se desafía con vehemencia la obligación internacional de juzgar a los perpetradores por graves vioalciones de derechos humanos (...) los sobreviventes q'eqchi' no solo rechazan un procedimiento judicial en los términos de justicia penal ordinaria, sino que además quieren evitarlo, por el miedo a que la lógica interna del cosmos caiga sobre ellos. En este contexto, entre los q'eqchi' existe con claridad un equivalente cultural de justicia retributivo y restaurativo, que fomenta una justicia transicional holística e integral, que debe ser reconocido». Más allá del peligro de que esta realidad cultural indígena pueda ser utilizada par ajustificar una cultura de la impunidad prevalenciente en Guatemala, surgen -para Lieselotte Vaiene- unas importantes preguntas finales: "¿cómo se pueden conciliar estas visiones y posturas enclavadas en un marco de referencia filosófico, epistemológico y ontológico que difiere mucho del supuesto consenso universal sobre las funciones y objetivos de justicia transicional, basados en el derecho internacional de los derechos humanos? (...) ¿cómo tienen que acutar el Estado y los actores internacionales con respecto a estos retos culturales al paradigma de la justicia transicional? (...) ¿cómo se deben tener en cuenta estas realidades culturales complejas en el diseoñ e implementación de intervenciones de justicia transicional?». Ella misma nos da las pistas para empezar a responderlas. Por un lado, parece importante que los académicos y profesionales -mayoritariamente formados en una versión occidental y antropocéntrica del derecho y las ciencias sociales- no se incomoden frente a estas realidades culturales, que contemplan dimensiones espirituales, como el rol de los ancestros, espíritus y fuerzas espirituales invisibles, y ello aunque exista la tentación -como demuestran las experiencias en varios países africanos a las que ya se ha hecho referencia- de enfocarse solamente en prácticas culturales entendibles, visibles y manejables. En todo caso, su incorporación debe tener en cuenta el peligro de imitación (mimicry) o estandarización al que se hizo referencia al principio de estas páginas. Por otro lado, parece necesario que los hallazgos de investigaciones antropológicas-jurídicas sobre el reconocimiento, incorporación y descentralización de ordenamientos jurídicos no estatales y sobre demandas de diversidad cultural se incorporen a las intervenciones para adaptar la justicia transicional más allá del paradigma hegemónico-dominante, como forma no solamente de garantizar la efectividad de la misma, sino también de tomarse en serio el respeto a los pueblos indígenas conforme a los propios estándares internacionales de derechos humanos. 
En todo caso, y más allá del contexto propio en el que se mueve el libro de Lieselotte Viaene, me gustaría volver, desde mi experiencia investigadora, al tema central de este capítulo: el dogma del castigo penal, y las posturas maximalistas que exigen el mismo en todo caso, por las violaciones de derechos humanos, especialmente en contextos transicionales en los que nos encontramos, en la mayoría de los casos, con las más graves. Este dogma no sólo plantea problemas dentro de las ontologías indígenas, sino mucho más allá. Respecto a las víctimas, parece evidente que las mismas no forman una psique unitaria, y que sus deseos, intereses y necesidades pueden variar de unas a otras. En este sentido, no resulta extraño que muchas de ellas pueden no tener especial interés en la persecución penal de los perpetradores. Pero es que, además, dichos deseos, intereses y necesidades pueden variar entre diferentes momentos para la misma víctima, especialmente en situaciones de conflicto o post-conflicto. En este sentido, los más importantes estudios sobre víctimas en este tipo de contextos demuestran como durante los primeros momentos -cuando la paz y la seguridad todavía no han sido alcanzadas- las prioridades de las víctimas no incluyen de forma especialmente relevante el castigo penal de los perpetradores. Creo que esta reflexión puede ayudar a explicar, por ejemplo, por qué el sí en el referendum sobre los acuerdos de paz entre el gobierno de Colombia y las FARC alcanzó cotas más altas, precisamente, en las zonas más golpeadas -y con más víctimas- por el conflicto.

Por supuesto, el castigo penal por las violaciones de los derechos humanos todavía podría justificarse en otros argumentos, como que una verdadera reconciliación es imposible sin persecución penal, o que el castitgo penal cumple unos fines valiosos en sí mismos, o incluso, en el cumplimiento de la legalidad internacional. El primero, me parece un argumento contrafáctico, y hay casos como el español o el uruguayo que posiblemente lo desmentirían, auque evidentemente eso requeriría determinar qué se entiende por reconciliación. Respecto al segundo, y sin descartar que los fines de la pena son valiosos en sí mismos, son muchos los autores que han manifestado sus dudas sobre la posibilidad de aplicar los fines de la pena ordinarios a los contextos que calificaré, siguiendo a Kant, de «mal radical» y en los que suele operar la justicia transicional. No me resisto, siendo filósofo del derecho, a citar, como ejemplo, la obra de Carlos Santiago Nino «Radical Evil On Trial», aunque la literatura sobre el tema es amplia y en muchos casos de gran finura argumentativa. Finalmente, todavía puede justificarse la expresión maximalista de la persecución penal en el cumplimiento de la legalidad internacional. A este respecto, no debe olvidarse que a parte de los esfuerzos nacionales, en los últimos años ha habido también una campaña de lucha contra la impunidad en la comunidad internacional y que se concreta sobre todo en la actividad de Naciones Unidas y en muchas de sus normas de soft law, aunque especialmente en el Conjunto de Principios Actualizado para la Protección y la Promoción de los Derechos Humanos mediante la Lucha contra la Impunidad (Doc. ONU E/CN.4/2005/102/Add.1) cuyo trabajo fue obra de la experta jurista Diane Orentlicher, sobre el primer draft redactado por el jurista francés Louis Joinet (Doc. ONU E/CN.4/Sub.2/1997/20/Rev.1). De cualquier forma, debe tenerse en cuenta, a mi modo de ver, que esa postura maximalista en cuanto a la persecución penal -así como la política de tolerancia cero respecto a las amnistías a la que me referí anteriormente- puede ser vista por las sociedades domésticas como una forma de imposición de valores por la comunidad internacional que tenga efectos perjudiciales no solamente en el entramado transicional sino también -especialmente reputacionales- respecto de la comunidad y los actores internacionales. No es de extrañar, en este sentido, que la propia Diane Orentlicher, después de defender dicha postura maximalista en un artículo publicado en la Yale Law Jornal (vol. 100, 1991, pp. 2537 y ss.) y titulado «Settling Accounts: The Duty to Prosecute Human Rights Violations of a Prior Regime» haya relativizado posteriormente su postura afirmando que la norma global de persecución penal debe ser matizada, de alguna forma, 
teniendo en cuenta el respecto que merecen las comunidades nacionales y locales desde el punto de vista de la diversidad cultural ("Settling Accounts Revisited: Reconciling Global Norms with Local Agency", The International Journal of Transitional Justice, vol. 1, 2007, pp. 10 y ss). Algo, que, por otro lado, parece estar en sintonía con las afirmaciones hechas por la autora del trabajo que aquí se reseña, siempre que se entienda que dicha matización no solo opera desde la comunidad internacional hacia los estados, sino también en el interior de estos últimos cuando hablamos de estados pluriculturales.

Pasando ahora al capítulo 5, titulado «El cortocircuito entre las intervenciones estatales y las realidades indígenas», éste identifica precisamente las fricciones existentes entre las políticas e intervenciones del Estado guatemalteco en materia de compensación-reparación y la realidad local de las comunidades indígenas. Para ello, se analizan los concepto legales de reparación, resarcimiento y compensación, así como los desafíos relativos a la delimitación legal y política de quiénes son los beneficiarios de los programas administrativos de reparación y desmovilización, desmilitarización y reintegración en el marco de un proceso de transición política. Finalmente, se discuten las percepciones tanto de víctimas como de ex-patrulleros q'eqchi' con respecto a los programas estatales de reparación.

Respecto al primero de los dos aspectos, el trabajo de Lieselotte Viaene parte de los estándares internacionales de derechos humanos y de la configuración de la reparación en los mismos para, posteriormente, aclarar algunas cuestiones semánticas relativas al uso de los términos reparación, resarcimiento y compensación en el caso del conflicto interno de Guatemala. Así, el término resarcimiento aparece por primera vez en el Acuerdo Global sobre Derechos Humanos de 1994 y, desde entonces, resarcimiento ha sido el término usado por el estado guatemalteco y la sociedad civil para hacer referencia a un programa estatal administrativo de reparaciones a las víctimas -el Programa Nacional de Resarcimiento (PNR)- aunque se acota a la compensación económica a las mismas. Mientras, el término reparación se utiliza para indicar la conjunción de la búsqueda de la justicia, los esfuerzos de búsqueda de la verdad y las iniciativas para recuperar la memoria histórica. Por su parte, el término compensación ha sido utilizado especialmetne por los ex-patrulleros para referirse al pago que consideraban que debían tener también como víctimas.

Ya anteriormente en esta revista (número 8, 2015, pp. 192 y ss) he analizado como los programas de reparación administrativos pueden tener ciertas ventajas sobre la reparación judicial, principalmente el tratarse de programas que no presentan algunas de las desventajas y costes asociados a la litigación judicial -como los retrasos a la hora de dictar sentencia, los altos costes de los procesos judiciales, la necesidad de presentar pruebas que superen el test judicial de admisibilidad, las cuestiones psicológicas asociadas al enfrentamiento con el victimario y a la revelación pública de los hechos, así como el riesgo de una posible decisión contraria a los intereses de las víctimas- y tener una consideración de la justicia bastante más amplia. Sin embargo, los programas administrativos de reparación también pueden tener problemas o dificultades, y el principal es al que Lieselotte Viaene hace referenica en las siguientes páginas del capítulo 5 , la definición del universo de víctimas que van a ser beneficiarias de los programas de reparación. En este contexto, el problema en Guatemala, donde no había espacio político para un Programa de Desarme, desmovilización y Reintegración (Programas DDR) de las PAC, fue la homogeneización -en inicio- de los ex-patrulleros como victimarios, sin tener encuenta, a pesar de las conclusiones de las iniciativas de búsqueda de la verdad en el país, que como ya se explicó anteriormente ese contexto específico suponía un quiebre básico de la dicotomía victima-victimario. En este sentido el informe de la $\mathrm{CEH}$ reconoce que los ex-patrulleros eran «cómplices forzados» y 
también, en muchos casos, víctimas pero la polarización política ha impedido en todo momento su inclusión como beneficiarios en los programas de reparación, con un apego a dicha dicotomía que puede calificarse de «lógicamente simplista, éticamente injusto, psicológicamente engañoso y prudentemente destructor». La exclusión de los patrulleros de los acuerdos de paz y la consecuencia de dicha exclusión -la ausencia de ningún tipo de resarcimiento o compensación a pesar de ser también víctimas en muchos casos- no se modificaría hasta el año 2003, cuando bajo el gobierno de Portillo, los ex-PAC y las viudas de ex-PAC realizó un primer pago a los mismos de un importe de unos 1.700 quetzales (240 dólares), que alcanzó a unas 190.000 personas. Este pago supuso la protesta airada de organizaciones de derechos humanos y otros actores y el desafío de la medida ante la Corte Constitucional del país, que la declaró inconstitucional en el año 2005. Ante este nuevo hecho, y ya bajo el gobierno de Berger, se institucionalizó la indemnización de los ex-patrulleros a través de la creación del Proyecto de reforestación Bosques y Agua para la Concordia, por el que se pagaría a los ex-PAC que se registrasen en el mismo a cambio de su trabajo en el programa con tres pagos, que en muchos casos no llegaron a completarse.

Paradójicamente, fue el conflicto político sobre el pago a los ex-patrulleros el que abrió el espacio político para la elaboración de un Programa Nacional de Resarcimiento (PNR. 2003) que estaba diseñado como una reparación integral a las víctimas y que incluía 5 medidas: restitución material, resarcimiento económico, reparación psico-social y rehabilitación, dignificación de las víctimas civiles y resarcimiento cultural. Es importante destacar que este programa excluye como beneficiarios del mismo a todos los ex-PAC inscritos en el registro del programa para el pago de los ex-patrulleros, aunque no hubieran recibido ningún pago. En este Programa Nacional de Resarcimiento se primó la reparación económica, que se situó en 24.000 quetzales (3.000 dólares) por un familiar fallecido y de 10.000 a 20.000 quetzales (1.370 a 2.750 dólares) por violación sexual y/o tortura. En cuanto a su implementación, todavía hay muchas zonas oscuras sobre el número de beneficiarios a los que alcanzó y otras cuestiones.

En cuanto a las percepciones de los sobrevivientes q'eqchi' sobre los programas estatales de reparación, los datos etnográficos revelan que ambos programas estatales de reparación interfieren y debilitan los frágiles procesos de reconstrucción social, agitando las emociones, la desconfianza y la conflictividad social.

Primeramente, se analizan las múltiples percepciones alredor del programa de compensación a los ex-patrulleros. En este sentido, el estudio llega a una conclusión doble respecto de las víctimas. Por un lado, hay entre las víctimas una conciencia cada vez mayor de que éstos fueron obligados a participar en el conflictos y que también sufrieron. Por otro, las víctimas expresan frustración y decepción por la mayor rapidez con la que se tramitaron las ayudas para los ex-patrulleros en comparación con las suyas propias, por el hecho de que muchas no entendían que el gobierno premiase con una compensación económica a quienes habían sido corresponsables de su ninla rahilal, y por lo que entienden que es un agravio comparativo teniendo en cuenta los diferentes tipos de sufrimientos de uno y otro grupo.

Entre los ex-PAC, la mayoría de los entrevistados consideran que merecen el pago porque fueron obligados a patrullar y mientras lo hacían no podían trabajar y abastecer a sus familias. Sin embargo, se han producido muchas quejas en relación a los problemas burocráticos que los ex-PAC tienen que afrontar, como la exclusión por carecer de documentos exigidos, que ha dejado a muchos de ellos y sus viudas sin el acceso a la compensación o la exclusión del PNR por estar en el registro del 
programa de los PAC a la que se hizo mención anteriormente. Además, la gran mayoría nunca recibió el pago total, sino solamente algunas cuotas del mismo y muchos consideran que al hacerse a cambio de un trabajo no supone, en sí misma, una compensación por su sufrimiento.

De nuevo, el desigual tratamiento que hacen los gobierno de guatemala entre victimas y ex-patrulleros -a pesar de que muchos son víctimas, incluso de diferentes bandos- no sólo genera malestar entre los diferentes tipos de sobrevivientes q'eqchi', «sino también fricciones y desconfianza en las comunidades. De hecho, el diseño y tratamiento específico de ambos programas revictimizan a las víctimas y a los Ex PAC», a lo que ayuda también el hecho de que las principales ONG del país especializadas en la atención psicosocial de las comunidades afectadas excluyen a los ex-patrulleros de sus programas en esa consideración exclusiva, limitada y limitante de los mismos como victimarios.

Posteriormente, se analiza cómo los ejecutores del PNR tuvieron que hacer frente los problemas y desafíos relativos a la traducción al q'eqchi' de conceptos tales como «reparación», «resarcimiento» y «restitución», que en palabras de la autora, demuestran «una clara falta de ejercicio de traducción intercultural o de doble vía como parte de un diálogo intercultural entre estado y sobrevivientes indígenas para crear políticas públicas de justicia transicional que respondan a visiones y necesidades indígenas».

Finalmente, el capítulo 5 presenta un análisis del funcionamiento del PNR y de sus retos y problemas desde la mirada de los sobrevivientes q'eqchi' que demuestran la insuficiencia del PNR.

El primero de esos problemas -al que la autora se refiere como la «vida no tiene precio»- demuestra los grandes problemas que el resarcimiento económico presenta para los sobrevivientes q'eqchi', muchos de los cuales son extrapolables a otros grupos de víctimas. En primer lugar, porque el pago les genera un fuerte sentimiento de culpabilidad, algo que no es exclusivo de los sobrevivientes indígenas, y que de hecho ha pasado en muchos contextos transicionales, como por ejemplo en Argentina, donde hubo un gran debate entre las madres de los desaparecido porque un sector de este movimiento veían la compensación económica como un dinero manchado de sangre, como una forma de comprar su silencio. En segundo lugar, porque aunque el trámite para recibir cualquier medida de resarcimiento en en sí mismo gratuito, lleva aparejado múltiples gastos de pasaje, documentación, traductores, etc., especialmente relevantes en contextos de gran pobreza y exclusión social. Estos problemas se hacen más patentes en el caso de las comunidades indígenas, ya que carecen de documentos oficiales, o hay errores en los que poseen, como por ejemplo, en sus nombres y apellidos. Además, muchas víctimas tienen que enfrentar racismo y discriminación en su contacto con las autoridades estatales para conseguir dicha documentación, como puede ser el Registro Civil. Las beneficiarios son mayoritariamente q'eqchi', y sin embargo, las autoridades estatales tienen un muy limitado conocimiento de su idioma, a pesar de que la ley 19/2003 reconoce el uso oficial de los idiomas indígenas, por lo que en muchos casos tienen que contratar tramitadores que les ayuden con el papeleo. Todo esto supone una revictimización, en lugar de resarcir el pasado y sanar las heridas. Por otro lado, los datos empíricos demuestran que los beneficiarios perciben más el resarcimiento como una ayuda de parte del Estado que en términos de una auténtica medida de reparación y que en muchos casos llega demasiado tarde o incluso sigue sin llegar.

El segundo hace alusión a la «restitución de pertenencias destruidas». Los sobrevivientes q'eqchi' consideran que el estado les debería devolver o compensar 
por sus pertenencias materiales que fueron destruidas, que para ellos tienen también un significado espiritual. Además, esa devolución o compensación, conforme al sistema normativo indígena, debería ser del mismo valor de todas sus pertenencias perdidas. En este sentido, las entrevistas revelan que existe mucho disgusto entre los desplazados internos en cuanto a las casas que el programa está ofreciendo, al tratarse de casas de bloque que no compensan el valor (material y espiritual) de sus casas perdidas.

El tercero es la «restitución de tierras». Otra gran demanda de las víctimas es la entrega de títulos de terreno o tierra, especialmente importante para la recreación de sus vidas y para fomentar una nueva situación de tranquilidad y paz, sobre todo si se tiene en cuenta la unión de las comunidades indígenas con su territorio, que va más allá de lo físico e incorpora el elemento espiritual. El PNR exige la titulación de tierras como condición para poder solicitar la medida de restitución de la vivienda y ello ha provocado que muchas familias q'eqchi' quedasen excluidas de esta medida. Teniendo en cuenta la histórica inseguridad jurídica sobre sus tierras, los sobrevivientes q'eqchi' se encuentran en una situación extremadamente vulnerable frente a megaproyectos energéticos y extractivos. Aunque el PNR incluyó la medida de restitución de tierras, dicha política nunca fue una prioridad, y se ha limitado a la situación de los desplazados, reparando las consecuencias del conflicto armado, pero sin enfrentar la causa profunda de este conflicto que es el problema agrario y la titulación de las tierras en Guatemala.

El cuarto, las «reparaciones colectivas». Los datos etnográficos sugieren un respaldo generalizado a las medidas de reparación colectiva. Mientras que la compensación se ha realizado a nivel individual, los sobrevivientes critican y no comprenden ese caracter individual. Muchas víctimas indican que todos han sufrido el conflicto armado y no entienden las categorizaciones del PNR.

El quinto, la «recuperación de la memoria histórica local». Esta recuperación se manifiesta en las entrevistas como una necesidad para los sobrevientes, que consideran necesario divulgarla a nivel de las comunidades afectadas. Sin embargo, y a pesar de que en 1999 la CEH recomendó una campaña de divulgación de su informe final, ni la versión original ni la versión en q'eqchi' fueron finalmente divulgadas de forma masiva en Alta Verapaz. Diferente es la situación en el marco del Proyecto REMHI, donde se trabajó estrechamente con varias comunidades y que ha sido valorado muy positivamente por parte de muchos sobrevivientes. Por otro lado, diferentes iniciativas locales de recuperación de la memoria histórica no han recibido ningún tipo de reconocimiento oficial, lo que puede considerarse, según la autora, como una «falta de interés por parte del Estado [que] revictimiza a las víctimas».

Por último, el punto clave planteado por los entrevistados fue «la importancia del rol de lo espiritual en la sanación de las heridas del pasado». Rituales de sanación, anclados en la cosmovisión q'eqchi', podrían atender el problema de los espíritus de la gente desplazada que todavía deambulan por las montañas. Para ello, es necesario «regresar a los lugares donde cada quien se asustó y perdió su muhel (espíritu), para realizar sus rituales». El problema es que muchos de esos lugares son ahora propiedad privada, por lo que los sobrevivientes necesitan un permiso oficial para pasar a esos terrenos. Además, a pesar de la importancia de este tema para la cosmovisión indígena, las organizaciones que ofrecen ayuda psicosocial muestran, por lo general, una «falta de interés y de respeto por los recursos de sanación de los pueblos indígenas».

Todos estos problemas ponen de relieve para la autora que si los diseños institucionales de la justicia transicional no parten de las necesidades reales de las 
víctimas, incorporando además un enfoque intercultural cuando los beneficiarios son indígenas, las políticas de estado no solamente pueden fracasar, sino también minar los procesos locales de reconstrucción hasta revictimizar a los sobrevivientes.

Intento terminar ya estas líneas con unas breves referencias al apartado final, dedicado a "conclusiones y recomendaciones», que comparto plenamente y que pueden resumirse en tres.

Por un lado, el hallazgo crucial del estudio es que la percepción indígena se posiciona como una opción contrahegemónica al paradigma occidental dominante de la justicia transicional y de los derechos humanos y refleja modos diversos en los que los sobrevivientes indígenas se enfrentan a las secuelas de las graves violaciones de los derechos humanos desde una posición no de víctimas pasivas, sino de sobrevivientes activos con agencia, utilizando un conjunto híbrido de recursos de justicia transicional a nivel tanto individual, colectivo y espiritual basado no exclusivamente en su cosmovisión, sino que también se alimenta de la interacción con las intervenciones implementadas por el Estado y por actores externos, que mezcla tradición e innovación y demuestra la naturaleza adaptativa y no estática de las prácticas legales indígenas.

Por otro lado, desde la perspectiva concreta del caso de Guatemala, puede observarse como en los últimos veinte años después de la firma de los Acuerdos de Paz, la búsqueda de justicia, reparación, verdad y reconciliación nunca ha sido tomada en serio por la élite socio-política ladina que gobierna Guatemala, y si se han conseguido logros es gracias a los esfuerzos impulsados por las organizaciones de derechos humanos y el apoyo de la comunidad internacional. En todo caso, este estudio ofrece reflexiones que pueden ser interesantes para la evaluación de este proceso y su mejora. Un punto crucial para ello es asumir que el diseño transicional desarrollado ha sido realizado de arriba a abajo (top-down), con un enfoque principalmente legalista, con falta de participación de los sobrevivientes en la conceptualización, diseño y gestión de los mecanismos transicionales y con un planteamiento occidental que difícilmente encaja con la cosmovisión indígena. Ante esta situación, sería deseable consensuar, articular y coordinar con los diversos grupos de sobrevivientes -indígenas y no indígenas- una política pública de justicia transicional en Guatemala con un enfoque intercultural, centrado en los supervivientes, y en el que se promocionen los derechos colectivos de los pueblos indígenas. Especialmente interesante resultaría el respeto, por parte del Estado, a los derechos de consulta previa, libre e informada con los sobrevivientes indígenas sobre las medidas legales y administrativas en materia de justicia transicional, así como el cumplimiento de la obligación internacional de reconocer el derecho colectivo de los pueblos indígenas a la tierra, al territorio y a los recursos naturales, que continua siendo una deuda histórica pendiente en Guatemala. Igualmente, se exige un salto o evolución de la justicia transicional-centrada en las violaciones de derechos civíles y políticos- para incorporar también la seguridad, los derechos económicos, sociales y culturales y el desarrollo sostenible, transformándose en una justicia no meramente reparativa, y pasando también a ser una justicia transformadora. De otra forma, las políticas nacionales de justicia transicional no sólo no tendrán éxito sino que debilitarán los procesos de reconstrucción social local que están desarrollándose en las comunidades afectadas.

Finalmente, desde la perspectiva internacional de la justicia transicional, el análisis del caso de Guatemala brinda importantes reflexiones para muchos de los debates teóricos y prácticos en torno al futuro de la justicia transicional. Algunas de las conclusiones, en este sentido, son: 1) los mecanismos de justicia transicional deben organizarse de tal manera que estén adaptados a las realidades locales y, al 
mismo tiempo, fortalezcan a los sobrevivientes y las comunidades; 2) Las normas universales -globales- que cortan el campo de la justicia transicional deben acomodarse a la diversidad cultural y responder a las realidades locales. El reto es cómo abordar las muchas visiones de los objetivos de la justicia transicional, pero en todo caso, puede afirmarse que los argumentos culturales deben tomarse en serio, y a la vez, con cautela. Así, dichas prácticas no deben desconectarse de sus marcos ontológicos de referencia, algo que resulta difícil de hacerse si dichas prácticas se convierten en otro instrumento del toolkit de la justicia transicional y empiezan a replicarse o imitarse en diferentes contextos. Por otro lado, los saberes y las prácticas indígenas poco conocidas, como el papel de los antepasados y los fenómenos espirituales, no tiene que ser un obstáculo, a pesar de las incomodidades occidentales ante los mismos. Además, la participación de expertos independientes puede brindar una protección contra los juegos de poder de las autoridades tradicionales y contra la manipulación de la tradición con propósitos políticos. Igualmente, el reconocimiento del importante papel que la antropología jurídica -por ejemplo, a través de peritajes antropológicos- puede ayudar a identificar y traducir significados culturales y a asesorar sobre la forma de incorporar otras epistemologías; 3) A pesar de que determinados actores clave en el campo de la justicia transicional han reconocido la importancia de un enfoque holístico e integral de las intervenciones de justicia transicional, lo cierto es que el enfoque dominante tiende al diseño de mecanismos que abordan por separado sus diferentes objetivos. Parece necesario, en este sentido, tomarse en serio los enfoques de abajo a arriba (bottom-up) -que permiten entender mejor como para los sobrevivientes dichos objetivos están entrelazadosasí como la indivisibilidad entre las dimensiones locales e internacionales de la justicia transicional.

Hay un importante trabajo por hacer.

\section{Bibliografía}

Orentlicher, D. (1991). Settling Accounts: The Duty to Prosecute Human Rights Violations of a Prior Regime. Yale Law Jornal. vol. 100, pp. 2537 y ss.

Orentlicher, D. (2007). Settling Accounts Revisited: Reconciling Global Norms with Local Agency, The International Journal of Transitional Justice, vol. 1, pp. 10 y ss. 